\title{
Modelling Impact of Extreme Rainfall on Sanitary Sewer System by Predicting Rainfall Derived Infiltration/Inflow
}

\author{
$\underline{\text { T. Nasrin }}^{\text {a }}$, H. D. Tran ${ }^{\text {b }}$ N. Muttil ${ }^{\text {a }}$ \\ ${ }^{a}$ College of Engineering and Science, Victoria University, PO Box 14428, Melbourne, VIC, 8001, Australia; \\ ${ }^{b}$ School of Civil, Environmental and Chemical Engineering RMIT University, Australia \\ Email: tasnim.nasrin@live.vu.edu.au
}

\begin{abstract}
Extreme climate events are becoming more intense in Melbourne in recent years. This increasing intensity of excessive rainfall has an adverse effect on the sewer network by causing sewage overflow hazards. Extreme rainfall events increase flow into the sewer system, both directly (inflow) and through infiltration into sewer. As a result of this Rainfall Derived Infiltration and Inflow (RDII), Sanitary Sewer Overflows (SSOs) may occur. These SSOs carry inherent risks to human health as well as lead to environmental pollution.
\end{abstract}

This paper demonstrates a rigorous and efficient procedure of predicting RDII in a sewer system in Melbourne, Australia by using the Sanitary Sewer Overflow Analysis and Planning (SSOAP) toolbox. The SSOAP toolbox is a new freely available tool designed by the U.S. Environmental Protection Agency (EPA) for modeling of RDII. In the SSOAP toolbox, the U.S. EPA Storm Water Management Model (SWMM5) is incorporated for the hydraulic routing of the sanitary sewer system. For RDII flow estimation, SSOAP implements the synthetic unit hydrograph (SUH) method. In the literature, this procedure is recommended as the most accurate and industry standard methodology of determining RDII. The simplest SUH contains three triangular hydrographs to describe the fast, medium, and slow RDII responses. Each hydrograph has total of three parameters named $\mathrm{R}, \mathrm{T}, \mathrm{K}$. R is the fraction of rainfall volume entering the sewer system as RDII during and immediately after the rainfall event, $\mathrm{T}$ is the time to peak, and $\mathrm{K}$ is the ratio of the time of recession to $\mathrm{T}$. This method is known as the RTK unit hydrograph curve-fitting analysis.

In the SSOAP toolbox, the three main input data used for RDII prediction are flow, rainfall and sewershed data. The SSOAP toolbox analyses rainfall and flow data and identifies dry weather flow (DWF) and wet weather flow (WWF) periods. RDII flow components for storm events are defined by hydrograph decomposition of measured flow data. The tool estimates $\mathrm{R}, \mathrm{T}, \mathrm{K}$ parameters for each rainfall/flow monitoring event and generates RDII hydrographs.

This paper provides an in-depth description of RDII analysis using the SSOAP toolbox for a case study catchment in Glenroy suburb It is located within the larger Pascoe Vale catchment in northern Melbourne. It is a residential area. The main reason for choosing this particular area as the case study is that the sanitary sewer pipes are quite old; therefore, the problem of SSOs are common. Three flow meters were used for flow data collection and rainfall data were obtained from the Bureau of Meteorology for a nearby rain gauge station. As the downstream flow meter location is the most critical point (as it receives wastewater flow from the whole catchment), the paper focuses on flow data from the downstream flow meter location for the RDII analysis. Two storm events have been analyzed for calibration of the RDII unit hydrograph parameters (namely, the R,T,K parameters).

This paper presents a simple calibration procedure of RTK parameters. The SSOAP toolbox provides automated calibration using a visual approach. The main purpose of this automatic visual calibration is that the simulated RDII flows closely match the RDII time series generated by decomposing the measured flow data. The SSOAP toolbox is shown to be a useful software for RDII analysis, as the simple, interactive and visual approach facilitates easy determination of the R,T,K parameters, rather than use of the complicated numerical techniques used in the past. Moreover, this study demonstrates the accuracy of the generation of $\mathrm{R}, \mathrm{T}, \mathrm{K}$ parameters using this software. As part of future research, these $\mathrm{R}, \mathrm{T}, \mathrm{K}$ parameters or the RDII hydrographs will act as input to a sewer simulation model like SWMM5 for the hydraulic analysis of existing sewer system. This would help in identifying locations which are at risk or prone to SSOs.

Keywords: $\quad$ Extreme Rainfall, Sanitary Sewer Overflows (SSOs), RDII, SSOAP Software. 
Nasrin et al., Modelling impact of extreme rainfall on sanitary sewer system by predicting rainfall derived infiltration/inflow

\section{INTRODUCTION}

According to the Intergovernmental Panel on Climate Change (IPCC) (Solomon, 2007), the global mean temperature has increased during the last 100 years. In their Fourth Assessment Report (AR4), the IPCC concluded with this hypothesis based on climate model simulations with different future greenhouse gas emission scenarios; it also affirms that the extreme rainfall trend will continue in the 21 st century (Willems et al., 2012). Rainfall trends indicate that extreme events are becoming more intense in Melbourne in recent years. This increasing intensity of excessive rainfall has adverse effects on urban water infrastructure by causing widespread flash floods and sewage overflow hazards (Jones et al., 2005, Hunter and Beck, 2011).

Rainfall Derived Infiltration and Inflow (RDII) is one of the major causes of SSOs. RDII is the stormwater that enters the sanitary sewer system in terms of stormwater inflow (SWI) and rainfall-dependent infiltration (RDI). SWI is the direct flow that occurs early during the rainfall events and enters the sewer pipes through direct connections. The sources of inflow are roof downspouts illegally connected to the sanitary sewers, holes in manhole covers, storm sewer cross-connections and so on. RDI is the runoff or flow that enters sewer pipes via damaged pipe sections, leaky joints or defective manhole walls after percolating through the soil (Karuppasamy and Inoue, 2012, Muleta and Boulos, 2008)

SSOs occur when there is insufficient capacity of the sewer system. Hence, in planning of sewer systems, it is important to have a better understanding of how RDII flows enter sanitary sewers and what effective measures should be taken to reduce these flows. In this paper, the Sanitary Sewer Overflow Analysis and Planning Toolbox (SSOAP) will be introduced to predict RDII for a residential catchment in Melbourne, Australia. RDII is important because sanitary sewers are designed to accommodate some inflow and infiltration. As a consequence of extreme rainfall events, this allowance is frequently exceeded by extraneous flows (Vallabhaneni et al., 2008).

The SSOAP software applies the most common RTK synthetic unit hydrograph method for RDII flow estimation using rainfall records and sewer flow monitoring data. Unit hydrograph (UH) parameters are calibrated by using synthetic UH curve fitting analysis. In the past, calibration of RDII unit hydrograph parameters are done by a tedious and inexact trial-n-error process, and manually adjusted. Genetic Algorithm (GA) optimization technique is also used to calibrate R, T, K parameter that match simulated RDII with measured RDII (Muleta and Boulos, 2008). SSAOP simplifies long calibration procedure of R, T, K parameters by providing automatic calculation and most important easy to use visualization of data (Mikalson, 2011). SSOAP tool seems a good alternative estimation procedure of RDII compare to other evaluation methods proposed in the literature.

\section{THE STUDY AREA}

The case study catchment is the Glenroy subcatchment in northern Melbourne, which is a residential area. The location of study area and the layout of Glenroy sewer network including flow meters point (manholes) are shown in Figure 1. The length of major sewer pipes is approximately $3.2 \mathrm{~km}$. The pipe material is concrete. Three manholes were used for flow monitoring in November-December 2010. Upstream manholes are GLN23 and GLN17, and downstream manhole is GLN8. The paper focuses on flow data from the downstream manhole, GLN 8 for RDII analysis. It is taken as the study area because the sewer network is old; the pipe age being approximately 74 years. Due to the aging pipe, it is expected that the sewer pipe has cracks and joint defects and

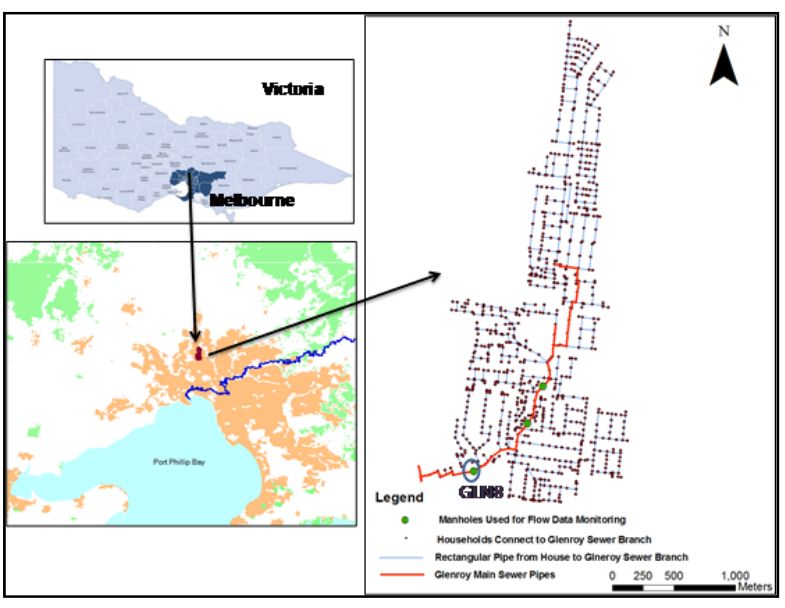

Figure 1. Glenroy sewer network hence, the problem of SSOs are common. 
Nasrin et al., Modelling impact of extreme rainfall on sanitary sewer system by predicting rainfall derived infiltration/inflow

\section{APPLICATION OF SSOAP}

\subsection{Overview of SSOAP Toolbox}

The SSOAP toolbox is relatively a new computer software tool which implements a rigorous and efficient procedure of predicting RDII. In the SSOAP toolbox, the U.S. EPA Storm Water Management Model (SWMM5) is incorporated for the hydraulic routing of the sanitary sewer system.

Figure 2 depicts the overview of functional tools within the SSOAP Toolbox, and the flow of data through the analysis and planning process. According to (Vallabhaneni and Camp, 2007), several, functional tools are integrated into SSOAP . These are as follows:

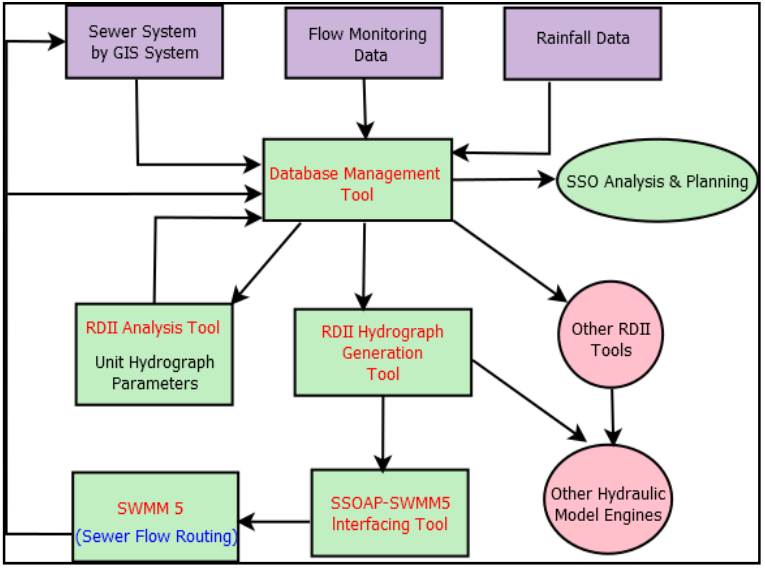

Figure 2. Activity flow diagrams for the functional tools within the SSOAP toolbox (Vallabhaneni and Camp, 2007)
iii) RDII Hydrograph Generation iv) SWMM5 Interfacing
i).Database Management
ii) RDII Analysis Tool

The database management tool (DMT) helps to manage, store and organize data in a standard Microsoft Access ${ }^{\circledR}$ database named SSOAP System Database (SSD). DMT efficiently performs quality assurance and quality control (QA/QC) and analyzes the data used in the SSOAP Toolbox. It also reviews, edits and corrects suspicious records and estimates missing data by interpolation. In order to predict RDII, the SSOAP toolbox acts two major functions; such as, hydrograph decomposition and R, T, K unit hydrograph curve fitting. These two major functions are performed by the RDII analysis tool. The RDII hydrograph generation tool prepares RDII inflow hydrograph using R, T, K parameters (determine by the RDII analysis tool) and sewershed area (stored in SSD).

\subsection{Hydrograph Decomposition}

Hydrograph decomposition is a method of estimating the different wastewater flow components in the sewer system. The decomposition process is used to determine the sources of flow and RDII characteristics. There are three basic wastewater flow components in a sewer system described below:

- Base Wastewater Flow (BWF): BWF is base wastewater flow from residential, commercial, and industrial areas and releases to a sanitary sewer system for collection and treatment.

- Ground Water infiltration (GWI): GWI means the groundwater that enters the collection system through defective pipes, pipe joints, and leaking manhole walls. It happens when the water table exceeds the hydraulic grade line of the sewer contents.(Mikalson, 2011)

- Rainfall Derived Infiltration and Inflow (RDII): RDII is the rainfall-driven flow which enters sewer network in direct response to the intensity and duration of rainfall events. It occurs during and following rainfall events, and ends when the flow pattern returns back to the pre-rainfall level (Vallabhaneni et al., 2008).

A schematic of the steps involved in hydrograph decomposition is given in Figure 3. It is the procedure of separating wastewater flows into base flow (including GWI) and RDII components. Dry Weather Flow (DWF) means waste water flow contains Base flow including GWI. Wet weather flow (WWF) is the combination of DWF and RDII. RDII component for each

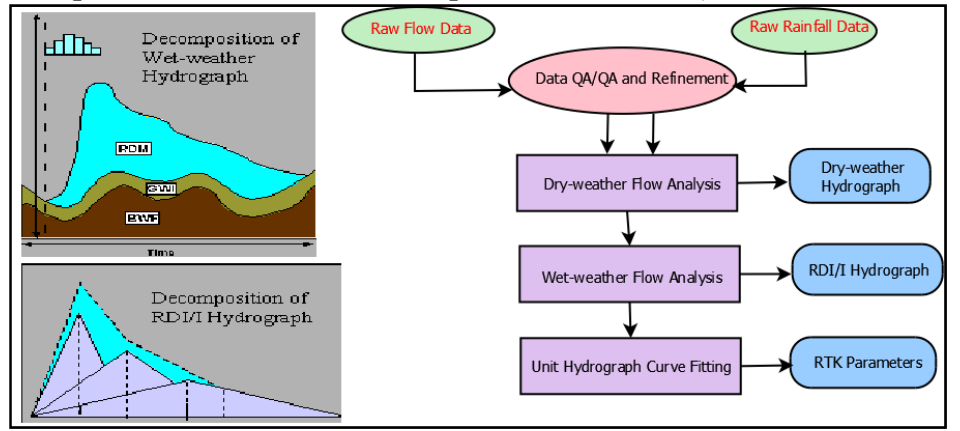

Figure 3. Wastewater component and hydrograph decomposition approach (Vallabhaneni and Camp, 2007) storm event are defined by subtracting the DWF hydrograph from WWF hydrograph. This difference is the volume of rainfall entering the sewer network during the storm event (Karuppasamy and Inoue, 2012). 
Nasrin et al., Modelling impact of extreme rainfall on sanitary sewer system by predicting rainfall derived infiltration/inflow

\subsection{RTK Unit Hydrograph (UH) Curve Fitting Analysis}

The synthetic unit hydrograph (SUH) method (or RTK method) is used to simulate RDII flows like any other unit hydrograph method applied in storm water runoff analysis. A unit hydrograph means the flow resulting from one unit of rainfall during one unit of time (Vallabhaneni and Camp, 2007). This unit hydrograph curve fitting analysis is based on fitting three unit hydrographs to measure RDII by hydrograph decomposition procedure. Each unit hydrograph, shown in Figure 4, is characterized by the three sets of R, T, K parameters. According to (Vallabhaneni and Camp, 2007, Karuppasamy and Inoue, 2012, Muleta and Boulos, 2008), the $\mathrm{R}, \mathrm{T}$ and $\mathrm{K}$ parameters are defined as follows:

- R parameter represents the fraction of the total rainfall volume that enters the sewer system as RDII. The sum of three unit hydrograph (R1, R2, and R3) allocates total R value for the storm event.

- T parameter represents the time from the onset of rainfall to the peak of the UH in hours

- K parameter represents the declining portion of the triangular unit hydrograph. $\mathrm{K}$ represents the ratio of time to recession.

The first triangle represents the most rapidly responding storm water inflow and has a $\mathrm{T}$ value of one to three hours. The second triangle includes both storm water inflow and rainfall-dependent infiltration and has a longer $T$ value. The third triangle is a rainfall dependent infiltration (long term delayed infiltration). It may continue long after the end of storm event and has the longest $\mathrm{T}$ value. The steps of this unit hydrograph methodology are the determination of $\mathrm{R}, \mathrm{T}, \mathrm{K}$ parameters for one unit of rainfall, shown in Figure 4, and then summation of all the RDII hydrographs within a storm event.

The SSOAP Toolbox automatically sums the unit hydrographs and generates simulated total RDII hydrographs. The graphical tool in the SSOAP toolbox helps to identify the best

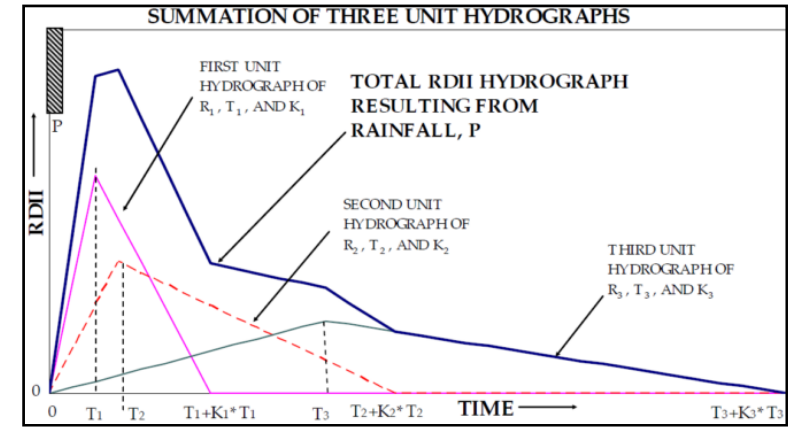

Figure 4. RTK Synthetic Unit Hydrograph approach (Vallabhaneni and Camp, 2007) combination of the R, T, and $\mathrm{K}$ values for each of the three triangular unit hydrographs (Vallabhaneni and Camp, 2007). This visual curve fitting is accomplished by iterations and continued until a good visual comparison between the simulated RDII hydrograph and the observed RDII hydrograph is achieved. Moreover, the numerical comparison of total RDII volume with the sum of volume under each of the unit hydrographs will validate that the curve fitting is done successfully. Figure 5 shows the curve fitting procedure of three unit hydrographs in the SSOAP toolbox.

Although the synthetic unit hydrograph method or the RTK method is widely used to analyze and predict RDII, it has some limitations when compared to the runoff routing methods. They

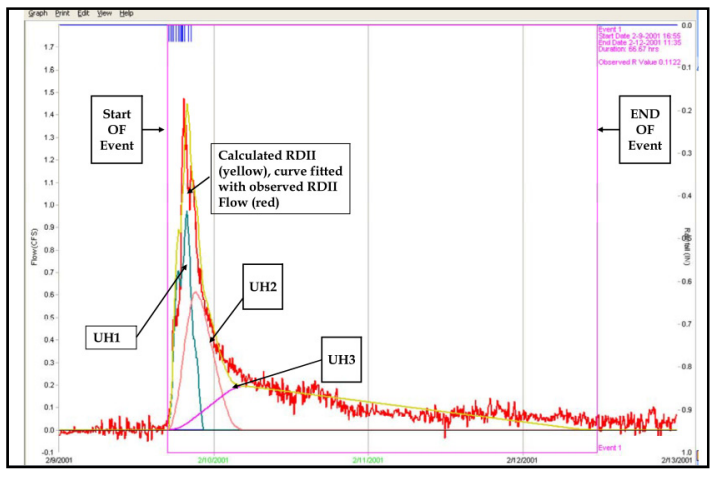

Figure 5. Unit hydrograph curve fitting analysis in SSOAP Interface (Vallabhaneni and Camp, 2007) are not physically based and the parameters are simply non-physical and hence if the system changes, the effect cannot be predicted by the unit hydrograph method. Routing models are used to extrapolate the limited monitored data to predict RDII flows under future urbanization conditions. The RDII prediction method which is selected in these models, must be amendable for estimating current sewer flows and projecting the change of sewer flows in response to sewer system expansion and aging, and RDII control measures (Vallabhaneni and Camp, 2007).

With the SUH method, it is not easy to expand the limited monitored data to existing and future urbanization conditions. Statistical methods complementing RTK approach are used to extrapolate the sewer system RDII response. It is developed based on the observed R-value relationship with event rainfall depth, antecedent one-month precipitation and GWI. The resulting regression equation helps to predict RDII for unmonitored 
Nasrin et al., Modelling impact of extreme rainfall on sanitary sewer system by predicting rainfall derived infiltration/inflow

and design storms. The extrapolated R-values must take into account the physical reality. Sometimes, it is difficult to get reliable results (Vallabhaneni and Camp, 2007).

\section{RDII MODELLING METHODOLOGY IN CASE STUDY USING SSOAP}

\subsection{Data Collection and Analysis}

Climate, topography, and hydrology data for this study area were collected from different Australian Government authorities: namely, climate data from Bureau of Meteorology (BOM); geographic information system (GIS) data regarding the existing sewer network, long-term flow data, etc. from Yarra Valley Water (who manage the case study catchment).

The three major data required for RDII prediction are flow data, rainfall data and sewershed data. The SSOAP toolbox defines an empirical relationship between rainfall and the collection system using this input data i.e. flow and rainfall monitoring data (Vallabhaneni and Camp, 2007). Physical sewer system data/hydraulic data are primarily needed for hydraulic modeling using SWMM5 or other models.

Table 1. Data description

\begin{tabular}{|l|l|}
\hline Data Type & Specific Requirements \\
\hline $\begin{array}{l}\text { Rainfall } \\
\text { Data }\end{array}$ & $\begin{array}{l}\text { Rainfall (mm, in) } \\
\text { Time step (minutes) }\end{array}$ \\
\hline Flow Data & $\begin{array}{l}\text { Flow Rate (cfs, cms, gpm, Lps, MGD } \\
\text { or MLD) } \\
\text { Contributory Area (ac., ft2, ha, m2 or } \\
\text { mi2) } \\
\text { Velocity (ft/s or m/s) } \\
\text { Depth (ft, in. or m) } \\
\text { Time Step (minutes) } \\
\text { Total Length of Sewer (linear ft) }\end{array}$ \\
\hline $\begin{array}{l}\text { Sewershed } \\
\text { Data }\end{array}$ & $\begin{array}{l}\text { Sewer Service Area (ac., ft2, ha, m2 or } \\
\text { mi2) }\end{array}$ \\
\hline
\end{tabular}

Table 1 shows some details of these datasets (with specific requirements) used in the SSOAP toolbox. In the SSOAP toolbox, flow data and rainfall data should always have the same time step in order to predict RDII for overflow analysis. All data from the Glenroy study catchment have a 6-minute time step.

\subsection{Hydrograph Decomposition of Flow Data}

The SSOAP toolbox separates measured waste water flows into dry weather flow components and RDII flow components. Dry weather flow components consist of base flow including GWI. This separation procedure is done by hydrograph decomposition of observed flow data. Figure 6 represents decomposition of the observed flow into DWF and RDII components during a rainfall event. A schematic of the steps involved in hydrograph decomposition is given below.

\subsubsection{Dry-Weather-flow (DWF) Analysis}

The SSOAP toolbox determines automatic DWF day by DWF analysis and finds the characteristic weekday and weekend DWF diurnal curve patterns in downstream flow meter location. Rainfall data helps to identify dry weather periods during flow monitoring periods. Figure 7 depicts weekday and weekend DWF hydrographs. The results can be shown graphically and statistically. These DWF will be used to perform wet-weather flow analysis.

\subsubsection{Wet-Weather-flow (WWF) Analysis}

SSOAP determines RDII events automatically by wet weather flow analysis. WWF analysis means to select major rainfall events. The RDII Analysis Tool determines RDII event's start and end times based on flow monitoring data and corresponding rainfall records. 
Nasrin et al., Modelling impact of extreme rainfall on sanitary sewer system by predicting rainfall derived infiltration/inflow

Major storm events have chosen based on the largest volume and quick response of flow recorded by the flow meter (Karuppasamy and Inoue, 2012). In this study, two storm events have been selected for SSOAP analysis. Figure 8 shows the selected rainfall events and the measured flow at the downstream flow meter (GLN8). The selected storm events are (1) November Storm: 27.11 .2010 (17:48 pm) to 28.11.2010 (14:48 pm) and (2) December Storm: 08.12.2010 (09:36 am) to 09.12.2010 (10:06 am)

\subsection{Hydrograph Decomposition and Unit Hydrograph Curve Fitting Analysis}

Figure 8 shows decomposition of the wet weather flow into DWF and RDII components during a rainfall event. RDII hydrograph is calculated by subtracting DWF (base flow including GWI) from total WWF (DWF+RDII).

The SSOAP toolbox simplifies the long calibration procedure of RTK parameters by providing automated

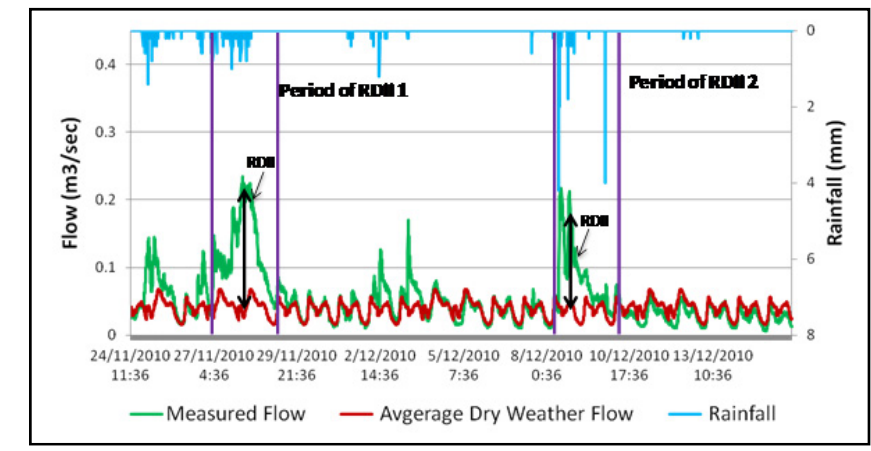

Figure 8. Determination of RDII event hydrograph calculation using a visual approach. The graphical tool helps to identify the best combination of the R, T, and $\mathrm{K}$ values for each of the three triangular unit hydrographs The visual curve fitting is accomplished by iteration and it continues until the simulated RDII flows closely match the RDII flows generated by decomposing the measured flow data. Figure 9 shows the visual calibration of unit hydrograph parameters (RTK) for one of the selected events (December storm).

Table 2 depicts three sets of calibrated RTK parameters (total nine parameters) for the two storm events. The $\mathrm{R}$ value is the fraction of rainfall from a storm event and the sum of $\mathrm{R} 1+\mathrm{R} 2+\mathrm{R} 3$. A high R1 means the RDII is inflow driven. If the portion of R2 and R3 is more in the total $\mathrm{R}$, that indicates RDII is preliminary infiltration driven. $\mathrm{T}$ and $\mathrm{K}$ values are not varying greatly between wet weather events. They are assigned for iterative process and the values are changed until they best "fit" the RDII event hydrograph (Karuppasamy and Inoue, 2012). In summary, higher $\mathrm{R}$ value indicates more inflow and infiltration that is entering the sewer network.

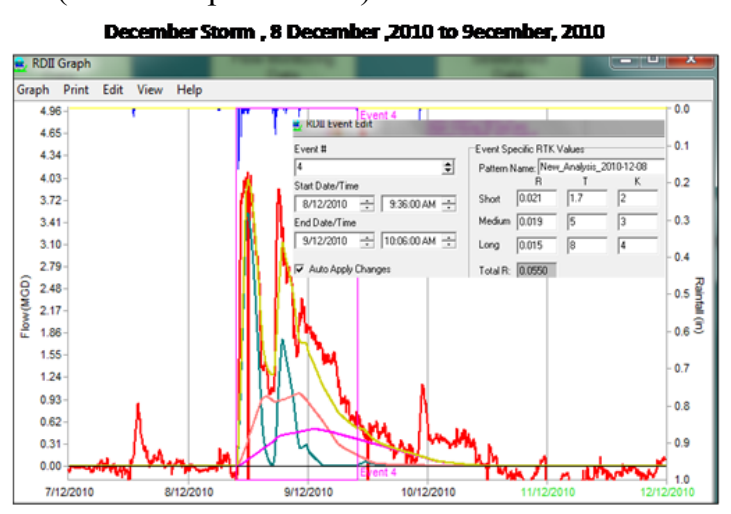

Figure 9. Calibration of RTK parameters using SSOAP

For GWI, the factor can be calculated by the ratio of the measured average dry weather flow to the metered water consumption. The normal expected range is mentioned as 0.7 to 0.9

Table 2. RTK parameters at GLN8 manhole (flow meter) in Glenroy

\begin{tabular}{|l|c|c|c|c|c|c|c|c|c|c|}
\hline $\begin{array}{l}\text { Storm } \\
\text { Event }\end{array}$ & $\mathrm{R} 1$ & $\mathrm{R} 2$ & $\mathrm{R} 3$ & $\begin{array}{c}\text { Total } \\
\mathrm{R}\end{array}$ & $\mathrm{T} 1$ & $\mathrm{~T} 2$ & $\mathrm{~T} 3$ & $\mathrm{~K} 1$ & $\mathrm{~K} 2$ & $\mathrm{~K} 3$ \\
\hline November & 0.021 & 0.028 & 0.035 & 0.084 & 1.5 & 3 & 4 & 1.6 & 3 & 8 \\
\hline December & 0.021 & 0.019 & 0.015 & 0.055 & 1.7 & 5 & 8 & 2 & 3 & 4 \\
\hline
\end{tabular}

(Carne, 2013). When the value is below 0.5 , it indicates exfiltration. When the value is greater than 1.2 , it is indicative of significant groundwater infiltration. GWI is determined by the SSOAP software. The RDII analysis tool in the software graphically divides the DWF into base flow and GWI. GWI can be determined through GWI monitoring or stream data analysis.

GWI can be measured by a GWI model. Infoworks SWMM offers a ground water model to determine GWI. It also provides unit hydrograph model for RDII prediction (Lockie and Joseph, 2008). The GWI model is more applicable for long term simulation and antecedent predictions. It gives more reliable results when physical parameters such as soil properties and ground water level are available. 
Nasrin et al., Modelling impact of extreme rainfall on sanitary sewer system by predicting rainfall derived infiltration/inflow

\section{DISCUSSION}

Fitness evaluation of the two calibration periods have been checked using the root mean square error (RMSE) measure. The RMSE for both the calibration periods are less than 0.05 , as shown in Table 3. Figure 10 depicts fitness evaluation of the two calibration periods by plotting sum of RDII flow and DWF, calculated in the SSOAP analysis, and the measured flow from GLN8 manhole.

The calibration shows a good match between the two flow patterns. Hence, the accuracy has been demonstrated for the two calibration periods visually as well as using the RMSE.

\section{CONCLUSIONS}

The SSOAP toolbox facilitates the analysis for quantification of RDII. The RTK method is the most popular and simplest SUH method, which has been used in the software. The simple, attractive and visual approach of the software develops easy determination of RTK parameters to

Table 3. RMSE for the 2 calibration periods

\begin{tabular}{|l|l|l|}
\hline Event & Calibration Period & RMSE \\
\hline Nov Storm & 27 Nov 2010- 28 Nov 2010 & 0.026 \\
\hline Dec Storm & 8 Dec 2010- 9 Dec 2010 & 0.017 \\
\hline
\end{tabular}

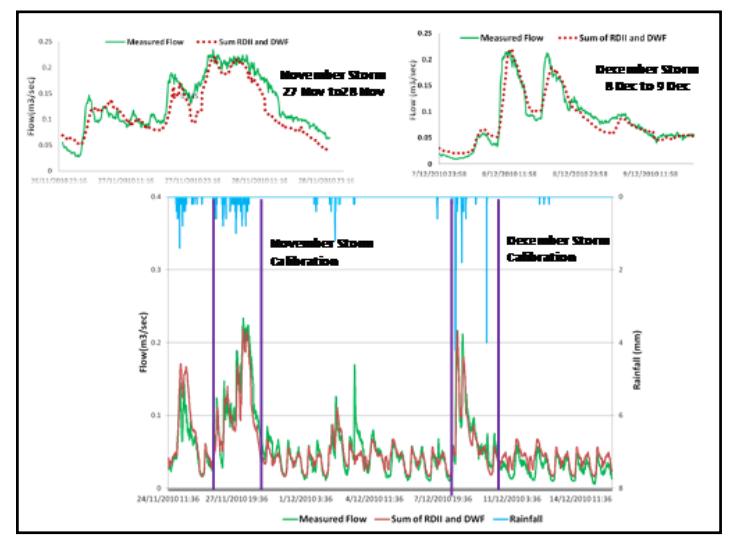

Figure 10. Fitness evaluation of the calibration simulate RDII, and reduces long calibration procedure. This resulting RDII will be used for a detailed dynamic flow routing to evaluate existing sewer system capacity, and provide cost-effective remedial solutions for controlling the existing SSOs problems.

\section{ACKNOWLEDGMENTS}

The authors thank Yarra Valley Water and Bureau of Meteorology for providing the necessary data.

\section{REFERENCES}

Carne, S. (2013). Cost-effective and Reliable Inflow-Infiltration Reduction -Have They Got It Right Down-Under? http://www.ghd.com/PDF/Cost-effective and Reliable II Reduction.pdf [Accessed ${ }^{\text {st }}$ October 2013].

Hunter, T. and Beck, M. (2011). Sewage reaches the bay again [Online]. The Age. Available: http://www.theage.com.au/victoria/sewage-reaches-the-bay-again-20110412-1denf.html [Accessed October 13].

Jones, R. N., Durack, P. J., Whetton, P., Howe, C. and Water, M. (2005). Implications of potential climate change for Melbourne's water resources, CSIRO Atmospheric Research, CSIRO Urban Water, Melbourne Water.

Karuppasamy, E. and Inoue, T. J. (2012). Application of USEPA SSOAP Software to Sewer System Modeling. World Environmental and Water Resources Congress @ sCrossing Boundaries, ASCE, 3494-3504.

Lockie, T. and Joseph, T (2008). Selection of an appropriate hydrological model to simulate inflow and infiltration. NZWWA Conference.

Mikalson, D. T. (2011). Development of Analytical Probabilistic Models for the Estimation of Rainfall Derived Inflow/Infiltration Frequency. Ph.D. thesis, University of Toronto.

Muleta, M. K. and Boulos, P. F. (2008). Analysis and calibration of RDII and design of sewer collection systems. The World Environmental \& Water Resources Congress, 1-10.

Solomon, S. (2007). Climate change 2007-the physical science basis: Working group I contribution to the fourth assessment report of the IPCC, Cambridge University Press.

Vallabhaneni, S. and Camp, D. (2007). Computer Tools for Sanitary Sewer System Capacity Analysis and Planning, US Environmental Protection Agency, Office of Research and Development.

Vallabhaneni, S., Lai, F.-H., Chan, C., Burgess, E. H. and Field, R. (2008). SSOAP-a USEPA toolbox for SSO analysis and control planning. World Environmental and Water Resources Congress, 1-10.

Willems, P., Arnbjerg-Nielsen, K., Olsson, J. \& Nguyen, V.(2012). Climate change impact assessment on urban rainfall extremes and urban drainage: methods and shortcomings. Atmospheric Research, 103, 106-118. 